\title{
Tüketici Sonrası Geri Dönüştürülen Denim Kumaşların Seçilmiş Konfor Özellikleri Üzerine Bir Çalışma
}

\author{
Füsun DOBA KADEM"1 ${ }^{*}$, Şehpal ÖZDEMIR ${ }^{1}$ \\ ${ }^{1}$ Çukurova Üniversitesi, Mühendislik Fakültesi, Tekstil Mühendisliği Bölümü, Adana
}

Geliş tarihi: 20.02 .2020

Kabul tarihi: 30.07 .2020

\section{$\ddot{\mathbf{O} z}$}

Denim, her yaştan ve her kesimden kullanıcıya hitap eden, dünya pazarında üstün rol oynayan bir kumaş çeşididir. Post-consumer re-cycle kavramı yani tüketici sonrası geri dönüşüm; hizmet süresini tamamlamasının ardından atılan tekstil malzemelerinin yeniden kullanılması işlemidir. Tüketici sonrası atıkların geri dönüşüm işlemi bu atıkların toplanmasını ve yeni giysilerde kullanılmak üzere bu atıklardan iplik üretilmesini kapsamaktadır. Bu çalışma ile bir denim işletmesinde, tüketici kullanımı sonrası geri dönüştürülen denim kumaşların hava geçirgenliği, eğilme dayanımı ve yıkamadan sonraki boyut değişimi standartlara göre tespit edilmiş ve elde edilen sonuçlara göre bu geri dönüşüm işleminin denim üretiminde etkin bir şekilde kullanılabileceği tespit edilmiştir.

Anahtar Kelimeler: Tüketici sonrası geri dönüşüm, Denim, Hava geçirgenliği, Eğilme dayanımı

\section{A Study on Selected Comfort Properties of Post-Consumer Recycled Denim Fabrics}

\begin{abstract}
Denim is a kind of fabric that plays an outstanding role in the world market and appeals to users from all ages and all walks of life. Post-consumer concept as is the process of reusing textile materials after completing the life cycle period. Recycling of post-consumer wastes involves the collection of waste and the production of yarn from these wastes for use in new clothing. In this study, air permeability, stiffness and determination of dimensional change during washing and drying of post-consumer denim fabrics was determined according to the standards. According to the results, this recycling process can be used effectively in denim production.
\end{abstract}

Keywords: Post-consumer recycle, Denim, Air permeability, Stiffness

\footnotetext{
${ }^{*}$ Corresponding author (Sorumlu yazar): Füsun DOBA KADEM, efsun72@cu.edu.tr
} 


\section{GíRiș}

Denim; yaş, cinsiyet, renk, 1rk, siyasi ve sosyal statü ayrımı olmaksızın, bireylerin birbirlerini eşit görebileceği tek giysi türü olarak, her yaştan ve her kesimden kullanıcıya hitap eden, Türk ve Dünya denim pazarında üstün rol oynayan bir tekstil ürünüdür. Geçmişte işçi kıyafeti olarak kullanılmaya başlayan, günümüze kadar hızlı bir değişim ve gelişim göstererek moda ve tasarım etkilerini en yoğun görebildiğimiz Denim ürünler, sürdürülebilirlik kapsamında, çevre dostu olma hedefiyle, üzerinde araştırmalar yapılan konuların başında gelmektedir.

Sürdürülebilirlik, çevre değerlerinin ve doğal kaynakların akılcı yöntemlerle kullanılması ilkesiyle ekonomik gelişmenin sağlanmasını amaçlayan çevreci dünya görüşü olarak tanımlanmaktadır. Tekstil ve hazır giyim sektörü özellikle son yıllarda çevresel zararlar, atıkların minimize edilmesi, yeniden kullanım (re-use, upcyle, down-cycle) ve geri dönüşüm (re-cyle) çalışmaları üzerine oldukça hızlı bir ivmelenme sergilemeye başlamıştır. Tekstil ve hazır giyim sektöründe sürdürülebilirlik kapsamında yapılmakta olan akademik çalışmalar gün geçtikçe artmakta ve sektörde yer alan işletmeler bu alanda geçmişe oranla daha duyarlı hareket etmektedirler.

Pamuk, dünyadaki en yaygın kar getiren gıda dışı mahsuldür. Üretimi dünya çapında 250 milyondan fazla kişiye gelir sağlamakta olup gelişmekte olan ülkelerdeki işçiliğin neredeyse \%7'sini kullanmaktadır. Tüm tekstillerin yaklaşık yarısı pamuktan üretilmektedir [1]. Tek bir pamuklu t-shirt için 2700 litre su harcanmaktadır. Dünya Yaban Hayatı Fonu, 1 kilogram pamuk üretmek için 20000 litre su gerektiğini, mevcut üretim yöntemlerinin sürdürülemez olduğunu, atılan giysilerden geri dönüşümle elde edilen pamuk kullanılarak tüketici sonrası geri dönüştürülmüş ürün ile saf pamuk ihtiyacının azaltılıp milyarlarca galon su tasarrufu sağlanabildiğini savunmaktadır [1].

Geri dönüşüm, atık malzemeleri yeni malzeme ve nesnelere dönüştürme işlemidir. Bir malzemenin geri dönüştürülebilirliği, bakir durumunda sahip olduğu özellikleri yeniden kazanma yeteneğine bağlıdır. Geri dönüşüm, modern atık azaltma sürecinde başlıca bileşenlerden olup, "azalt (reduce)-tekrar kullan (reuse) -geri dönüştür (recyle)" atık hiyerarşisindeki üçüncü bileşen olup günümüzde bu alanda önemli yol kat edilmiş hatta ileri dönüşüm (up-cycling) yapılarak süreç boyunca herhangi bir kalite kaybının yaşanmadığ1 üretimler de gerçekleştirilmiştir [2].

Tekstil üretim prosesleri büyük miktarda doğal kaynak (su, petrol, toprak) tüketimine sebep olmakta, toksik kimyasallar kullanılmakta ve bu durum karbondioksit açığa çıkarmaktadır. Buna ek olarak da her yıl milyonlarca ton tekstil atılmaktadır. Tekstil sektöründe bu atıkların minimize edilmesi ve geri dönüşümü üzerine birçok çalışma yapılmaktadır. Bu çalışmaya konu olan tüketici kullanımı sonrası geri dönüşüm yönteminin haricinde, tekstilde sürdürülebilirlik için kaynak kullanımını azaltma veya kullanılmayan eşyaların tekrar değerlendirilmesi gibi yollara da başvurulabilmektedir.

Giyim endüstrisinde geri dönüșüm, son y1llarda dikkat çekmeye başlamış, konfeksiyon endüstrisindeki perakendeciler, kullanılmış giysileri toplamak için çeşitli kuruluşlarla ortaklık geliştirerek geri dönüşüm stratejileri oluşturmaya ve tüketici sonrası geri dönüşüm ürünlerini destekler politikalar uygulamaya başlamışlardır. Giyim sektöründe geri dönüşüm, tüketici öncesi ve tüketici sonrası olarak iki şekilde gerçekleştirilebilmektedir. Tekrar kullanım, geri dönüşüm, kompostlama, yakma vb. işlemler ömrü biten giysileri bekleyen olasılıklardır. Tüketici eski giysiyi ihtiyacı olana verme veya üzerinde ufak değişiklikler yaparak giyme seçeneğinde karar kılarsa, giysi tekrar giyilebilmekte, eğer tekrar giyilebilme mümkün değilse geri dönüşüm şeklinde değerlendirilmektedir. Geri dönüşüm tesisisin bulunup bulunmadı $\breve{g} 1$, giysinin mevcut durumu, giysinin lif içeriği, giysinin tüketici tarafından ne derece kullanılmış olduğu vb. kriterlere bağlı olarak uygulanacak seçenek değişmektedir. 
Sürdürülebilir giysi talebinde bulunan müşteriler için giysinin etiketinde geri dönüşüm terimi kullanılarak tüketici dikkatini çekmeye yönelik uygulamalar firmaların önemsediği bir tercihtir. Şekil 1'de geri dönüşüm için uygulanan giysi üretim döngüsü görülmektedir.

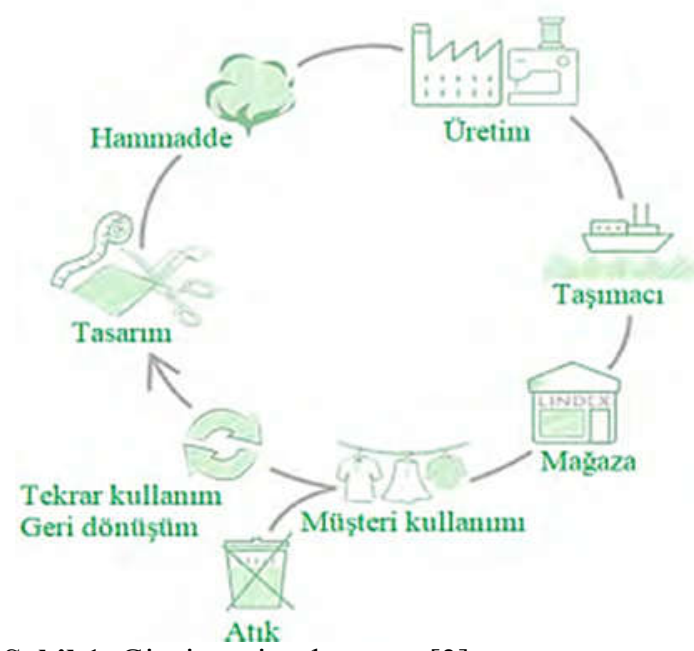

Şekil 1. Giysi üretim döngüsü [3]

Post-consumer re-cycle kavramı yani tüketici sonrası geri dönüşüm, sürdürülebilirlik kapsamında son zamanlarda ortaya çıkan bir kavramdır. Tüketici sonrası (PC) geri dönüşüm; tüketiciye ulaştıktan sonra hizmet süresini tamamlamasının ardından atılan tekstil malzemelerinin özellikle konfeksiyon ürünlerinin bir takım işlemlerden geçerek yeniden kullanılması işlemidir. Tüketici sonrası atıkların geri dönüşüm işlemi bu atıkların toplanmasını ve yeni giysilerde kullanılmak üzere bu atıklardan yeniden elyaf elde edilerek iplik üretim aşamasında belli bir oranda karışımda kullanılarak iplik üretilmesini kapsamaktadır ve böylece yeni k1yafetler üretilmektedir [4].

Tüketici kullanımı sonrası geri dönüştürülmüş elyaf kullanılarak elde edilen denim kumașın üretimi, standart denim kumaş üretimi gibidir. Farklı olan aşama, kullanılan ipliklerin, konfeksiyon atıklarından geri dönüşümle elde edilen elyafin \%15-20 gibi oranda harmana karıştırılarak iplik üretiminde kullanılıyor olmasidir.
Şekil 2'de genel olarak bir denim kumaş üretiminin elyaftan mamul kumaşa işlem aşamaları verilmiştir [4].

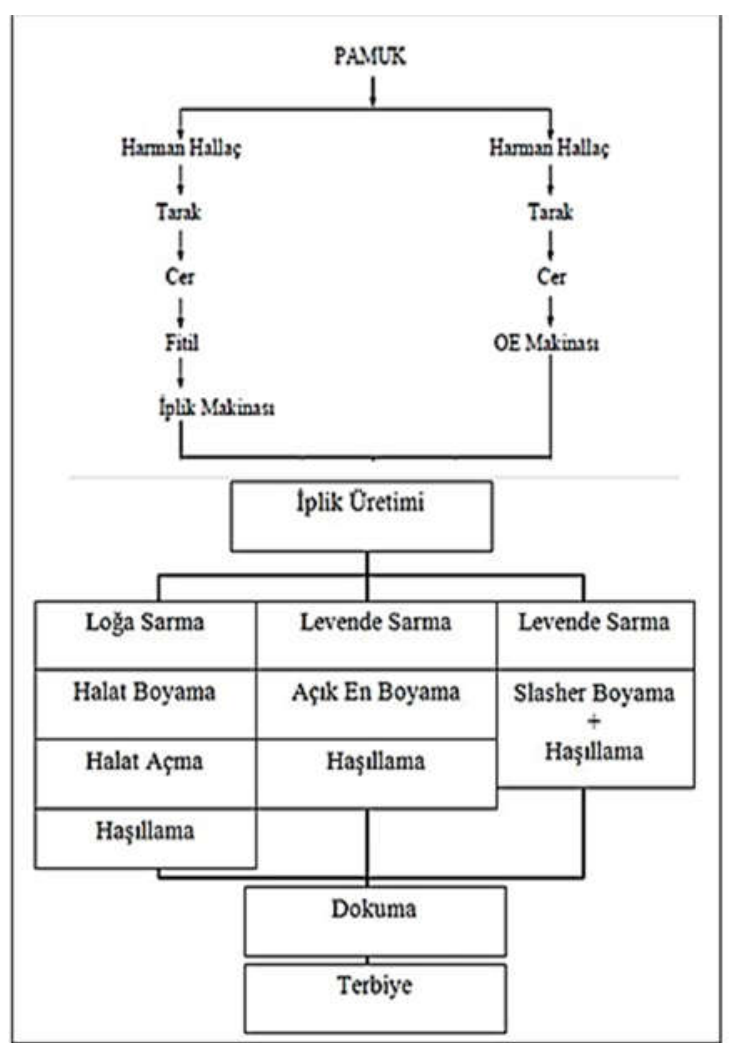

Şekil 2. Denim kumaş üretim aşamaları [4]

Konfeksiyon atıklarından geri dönüşümle elde edilen elyafin üretim yolculuğu söz konusu atıkların, balyalar halinde geri dönüşüm tesisine iletilmesi ile başlar. Geri dönüşüm tesisine gelen konfeksiyon atıkları ilk aşamada balyalarından açılır. Materyal, renk, elyaf kalitesi farklılığı ve tekstil içermeyen materyaller (etiket, rivet, fermuar vb. materyaller) bulunmas1 nedeniyle, heterojen yapıda olan konfeksiyon atıkları tasnif işlemi (ayıklama,ayırma vb.) ile yabancı materyallerinden ayrılır, üzerindeki dikişleri (varsa) sökülür. Daha sonra konfeksiyon atıkları küçük parçalara ayrılarak açıcılarda elyaf haline getirilir. Buradan çıkan materyal ikinci bir açıcıdan geçirilir. Tarak türünde olan bu makinede tek tek lif haline yani elyaf harmanına girebilecek duruma getirilerek balyalanır ve işlem tamamlanır (Şekil 3) [5]. 


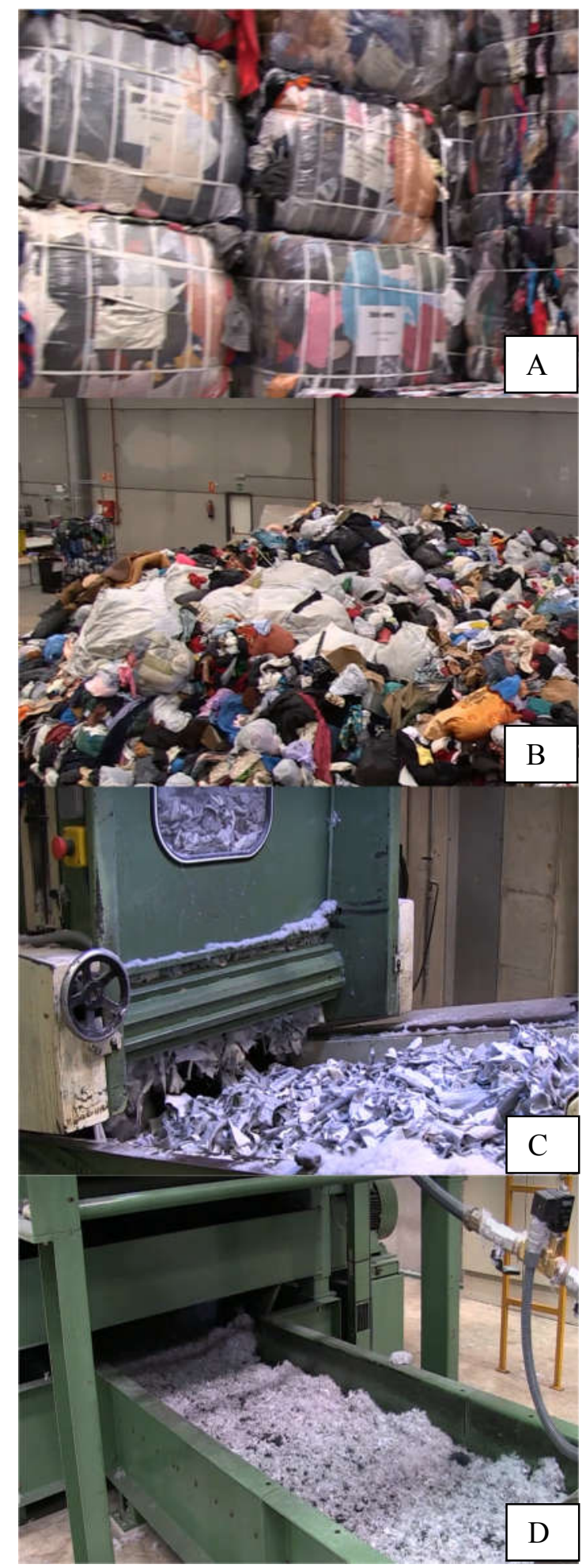

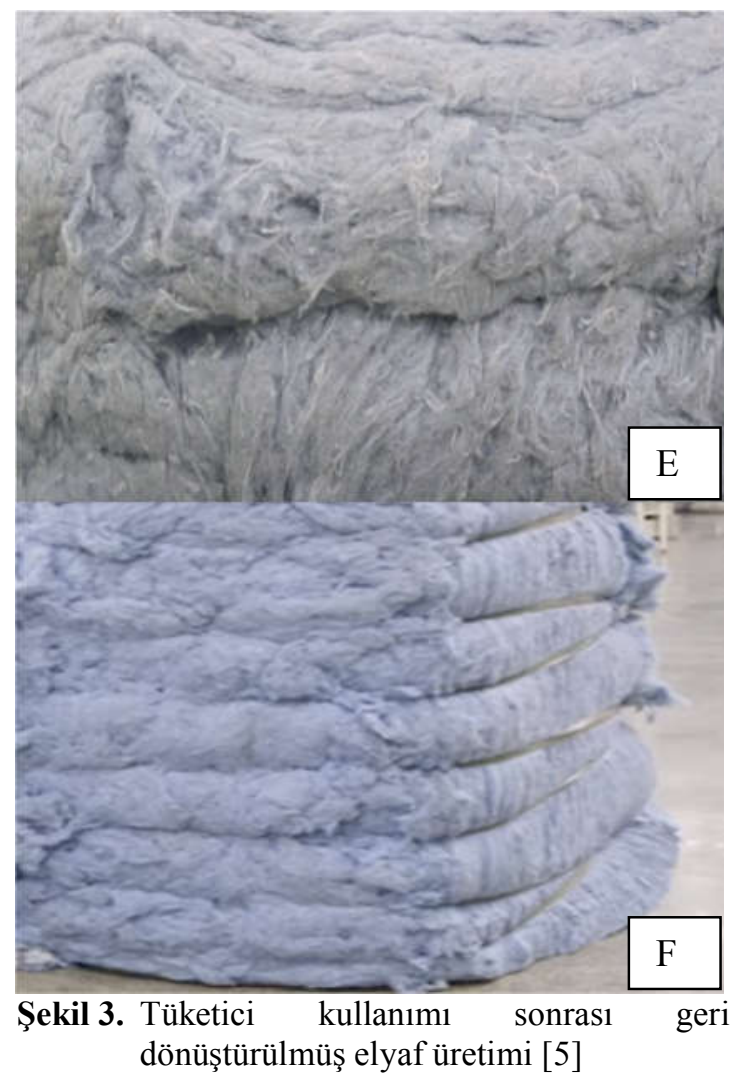

\section{2. ÖNCEKİ ÇALIŞMALAR}

Kurtoğlu ve diğerlerinin tüketici sonrası geri dönüşüm üzerine yaptıkları çalışmasında, hazır giyim ürünlerinin kumaş kırpıntılarından geri dönüşüm iplikler elde edilerek süprem kumaş üretilmiş ve bu kumaştan giysi dikilmiştir. Elde edilen geri dönüşüm ipliklerin, örme kumaşın ve giysinin kalite kontrol testleri yapılmış ve sonuçları geri dönüşüm olmayan kumaş ile karşılaştırılmıştır. Neticede, kumaş kırpıntılarının geri dönüşümü ile elde edilen ipliklerin başarılı bir şekilde hazır giyim sanayinde giysi üretiminde kullanılabileceğini ortaya koymuşlardır [6].

Doba Kadem [7], denim sektöründe pamuk atıklarının geri dönüşümü üzerine yaptığı deneysel çalışmada atkısı ve çözgüsü re-cyle pamukla harmanda karıştırılarak üretilmiş denim kumaş ile re-cyle olmayan denim kumaşın mukavemet özelliklerini karşılaştırmış ve neticede re-cyle 
pamuklu denim kumaşların da diğerleri gibi kullanılabileceği ortaya konmuştur.

Bairagi'nin tüketici sonrası konfeksiyon atıkları üzerine 20-30 yaş arası genç yaş grubu ile yapmış olduğu kapsamlı bir anket çalışmasında, nüfusun \%68'inin her ay giysiler için alışveriş yaptığı, satın alma dürtüsü ve fiili ihtiyacın temel olarak yeni giysilerin satın alma niyetinin arkasındaki nedenler olduğu tespitlerinde bulunmuştur. Ankete katılanların giysilerinin çoğunun, üst giysi ağırlıklı (gömlek gibi) 45'den fazla kıyafetten oluştuğu, bunların da üst giyim giysilerin yaklaşık \%88'i olduğu tespit edilmiştir. 20-30 yaş arasındaki ankete katılan kesimin \%53'ü giysilerini ihtiyaç olmadığı gerekçesiyle atmayı tercih etmiştir. Birkaç yıl önce, Hint evlerinde geri dönüştürülen kıyafetlerin çoğu, çantalar, battaniyeler, minder örtüleri, perdeler gibi tekrar kullanım (re-use) olarak diğer ürünlere dönüştürülmekteyken son zamanlarda, tüketici kullanımı sonrası konfeksiyon atıklarının geri dönüşümünden elde edilen giysiler üzerine daha fazla yoğunlaşıldığı görülmüştür [8].

Geri dönüştürülmüş pamuktan elde edilen denim kumaşların kuruma davranışının deneysel olarak değerlendirildiği Tölek ve Doba Kadem [9] tarafından yapılan bir başka çalışmada, orijinal denim kumaş ile geri dönüşümlü denimin kuruma davranışı deneysel olarak incelenmiş ve her ikisinin kuruma kapasitesinin benzerlik gösterdiği tespit edilmiştir.

Wangcheng Liub ve diğerleri [10], tüketici sonrası pamuk atığının çevre dostu alkalin/üre çözücü sistemleri kullanılarak kimyasal olarak geri dönüştürüldüğü çalışmalarında rejenere lifler üretmişlerdir. Elde edilen liflerin çapı, morfolojisi, 1sıl özellikleri ve gerilme özellikleri SEM, TGA, $\mathrm{XRD}$ ve gerilme testi ile karakterize edilmiştir. $\mathrm{Bu}$ çalışma ile çevre dostu solventler içeren tüketici sonrası pamuk atığının ekonomik bir geri dönüşüm yöntemi olduğu, mevcut ticari normal liflerle karşılaştırılabilir özelliklerine sahip liflerin üretilebileceği görülmüştür.

Doba Kadem ve Özdemir'in 2019 yılında tüketici sonrası geri dönüşüm denim üzerine hazırladıkları çalışmada, bir denim işletmesinde bu şekilde geri dönüștürülen denim kumaşların kopma mukavemeti ve sürtünme haslığı özellikleri standartlara göre tespit edilmiştir. Yapılan testler sonucu, harmana eklenen geri dönüşüm elyafın kumaş mukavemetinde çözgüde yaklaşık \%15 atkıda ise \%10 azalmaya sebep olduğu, ancak bunun kabul edilebilir sınırlarda olduğu değerlendirmesi yapılmıştır. Ayrıca sürtme haslığ 1 test sonuçlarında da her iki kumaşta da beklenildiği gibi haslık değerlerinin düşük çıktığı, geri dönüşüm kumaşların sürtme haslığının standart üretime kıyasla daha kötü olduğu görülmüştür [11].

$\mathrm{Bu}$ çalışmada, tüketici kullanımı sonrası geri dönüştürülerek üretilen elyaftan iplik üretilerek elde edilmiş denim kumaş, standart üretimdeki denim kumaşla kıyaslanmış ve kumaşların seçilmiş konfor özellikleri analiz edilmiştir.

\section{MATERYAL VE METOT}

Tüketici kullanımı sonrası toplanıp geri dönüştürülen elyafın orijinal elyafla harmanda karıştırılarak elde edildiği denim kumaş (PC denim) ile standart denim kumaşın (REF denim) bazı konfor özelliklerinin kıyaslandığı bu çalışmada yapılan testler ve sonuçları değerlendirilmiştir. Her numuneye hava geçirgenliği, yıkama ve kurutmada boyut değişmesinin tayini, eğilme dayanımı (Stiffness) ve dokunmuş tekstil mamullerinin eğilme dayanımı tayini testleri uygulanmıştır.

Çalışmada tüketici kullanımı sonrası geri dönüştürülen denim kumaşların üretiminde kullanılan atkı ve çözgü ipliklerine ait özellikler Çizelge 1'de verilmiştir.

Referans kumaş REF, tüketici kullanımı sonrası geri dönüştürülmüş kumaş PC ile ifade edilmiştir. Kumaşların üretiminde aynı harmandan pamuk iplikleri kullanılmıştır. Kullanıcı sonrası geri dönüşüm prosesinden elde edilen elyaf, çözgü ipliği harmanına \%20 oranında karıştırılmıştır olup \%79 pamuk elyafi referans denim ile aynı harmandır [12]. İki kumaş ta aynı terbiye işlemlerinden geçirilmiştir. Çizelge 2'de denim kumaşlara ait konstrüksiyon parametreleri ve 
kumaşların gördüğü terbiye işlem şartları verilmiştir. Numuneler, SEM-Taramalı Elektron Mikroskobu yardımıyla görüntü analizine tabi tutulmuş ve Çizelge 3 'te standartları verilen testler uygulanmıştır.

Çizelge 1. Denim kumaşların iplik özellikleri

\begin{tabular}{|l|c|c|c|c|}
\hline \multirow{2}{*}{$\begin{array}{c}\text { İplik Kalite } \\
\text { Değerleri }\end{array}$} & \multicolumn{2}{|c|}{ REF Denim } & \multicolumn{2}{c|}{ PC Denim } \\
\cline { 2 - 5 } & Çözgü & Atkı & Çözgü & Atkı \\
\hline Rkm $(\mathrm{km})$ & 15,16 & 16,82 & 16,11 & 17,21 \\
\hline U \% & 14,91 & 8,64 & 15,72 & 9,99 \\
\hline CVm & 7,43 & 6,02 & 6,68 & 7,05 \\
\hline $\begin{array}{l}\text { Eğrilebilirlik } \\
\text { İndeksi }\end{array}$ & 3,85 & 2 & 4,1 & 2,41 \\
\hline $\begin{array}{l}\text { İnce yer } \\
(-50)\end{array}$ & 1,95 & 0 & 8 & 0 \\
\hline Kalın yer (+35) & 47 & 13,89 & 321,5 & 90,5 \\
\hline Neps (200) & 16,42 & 11 & 201 & 73,5 \\
\hline Tüylülük & 9,06 & 7,11 & 8,7 & 6,87 \\
\hline
\end{tabular}

Çizelge 2. Kumaşların Konstrüksiyon Özellikleri

\begin{tabular}{|c|c|c|}
\hline $\begin{array}{l}\text { Numune } \\
\text { Özellikleri }\end{array}$ & REF Denim & PC Denim \\
\hline $\begin{array}{l}\text { Atk1 İpliği } \\
\text { Numarasi(Ne) }\end{array}$ & \multicolumn{2}{|r|}{10} \\
\hline $\begin{array}{l}\text { Çözgü İpliği } \\
\text { Numarası(Ne) }\end{array}$ & \multicolumn{2}{|r|}{7,12} \\
\hline $\begin{array}{l}\text { Atk1 S1kl1ğ1 } \\
\text { (tel/cm) }\end{array}$ & \multicolumn{2}{|r|}{20} \\
\hline $\begin{array}{l}\text { Çözgü } \\
\text { S1klığı(tel/cm) }\end{array}$ & \multicolumn{2}{|r|}{28} \\
\hline Örgü türü & \multicolumn{2}{|c|}{ 3/1 Z dimi } \\
\hline $\begin{array}{l}\text { Kumaş } \\
\text { Kompozisyonu } \\
(\%)\end{array}$ & $\begin{array}{l}\% 99 \text { pamuk } \\
\% 1 \text { elastan }\end{array}$ & $\begin{array}{l}\text { \%79pamuk } \\
\% 20 \text { post } \\
\text { consumer } \\
\text { recyle } \\
\% 1 \text { elastan }\end{array}$ \\
\hline Kumaş Eni(cm) & \multicolumn{2}{|c|}{135} \\
\hline $\begin{array}{l}\text { Terbiye İşlem } \\
\text { Şartları }\end{array}$ & \multicolumn{2}{|c|}{$\begin{array}{l}\text { Tek yüz yakma, Merserizasyon, } \\
\left.\text { (NAOH, } 18^{\circ} \mathrm{Bè}\right), 40^{\circ} \mathrm{C} \text { Yıkama, } \\
\text { Yumuşatıcı apre, Sanforizasyon }\end{array}$} \\
\hline
\end{tabular}

Hava geçirgenliği, kumaşların 1sınma, rüzgâr koruması ve nefes alabilirlik gibi özelliklerini belirleyen parametrelerden biri olduğundan, denim kumaşların bir konfor özelliği olarak bu çalışmada hava geçirgenliği tespit edilmiş ve REF denim ile PC denim birbirleriyle kıyaslanmıştır.

Yıkama ve kurutmada boyut değişmesinin tayini için, numunelere $9 \mathrm{~kg}$ kapasiteli ev tipi çamaşır makinesinde $40{ }^{\circ} \mathrm{C}$ 'de 45 dakika yıkama işlemi ve ardından düz bir zemine sererek kurutma işlemi uygulanmıştır. Yıkama-kurutma sonrasında kumaşların standartlara uygun şekilde boyutsal değişim oranları, sıklık, gramaj ve kalınlık değerlerinden oluşan fiziksel özellikleri ölçülmüştür.

Çizelge 3. Numunelere uygulanan analizler ve ilgili standartlar

\begin{tabular}{|l|l|}
\hline $\begin{array}{l}\text { Denim Kumaşlara } \\
\text { Uygulanan Analizler }\end{array}$ & İlgili Standartlar \\
\hline $\begin{array}{l}\text { Hava Geçirgenliği } \\
(\mathrm{mm} / \mathrm{s})\end{array}$ & $\begin{array}{l}\text { TS 391 EN ISO 9237, } \\
1999[13]\end{array}$ \\
\hline $\begin{array}{l}\text { Y1kama ve kurutmada } \\
\text { boyut değişmesinin } \\
\text { tayini (\%) }\end{array}$ & $\begin{array}{l}\text { TS EN ISO 5077, 2012 } \\
{[14]}\end{array}$ \\
\hline $\begin{array}{l}\text { Eğilme Dayanımı } \\
\text { (Stiffness) (kg-f) }\end{array}$ & ASTM D1388, 2018 [15] \\
\hline $\begin{array}{l}\text { Dokunmuş tekstil } \\
\text { mamullerinin eğilme } \\
\text { dayanımı tayini (cm) } \\
\left(45^{\circ} \text { Eğik Düzlem) }\right.\end{array}$ & TS 1409, 1973 [16] \\
\hline
\end{tabular}

Kumașların eğilme dayanımları 2 farklı metot ile analiz edilmiştir. Birinci yöntem olarak ASTM dairesel eğilme test metoduna göre dijital pnömatik yumuşaklık test cihazı ile ölçüm yapılmıştır.

Diğer yöntem olarak eğik düzlem metoduyla eğilme dayanımı, kumaşların sarkma uzunluğu değerlerinin kullanıldığ 1 formüllerle hesaplanmıştır [17]. Atk1 numunelerinden elde edilen sarkma uzunluklarının aritmetik ortalaması alınarak ortalama atk1 yönü sarkma uzunluğu $\left(\mathrm{X}_{\mathrm{a}}\right)$ ve benzer şekilde çözgü numunelerinden de ortalama çözgü yönü sarkma uzunluğu $\left(\mathrm{X}_{\mathrm{c}}\right)$ hesaplanmıştır. Eşitlik 2 ve 3 ile her iki denim kumaş türünün eğilme dayanımları tespit edilmiştir. Burada, a atkı yönü ç çözgü yönünü ifade etmektedir.

$\mathrm{C}=\mathrm{X} / 2$

$\mathrm{C}=$ Eğilme uzunluğ $\mathrm{u}, \mathrm{cm}$

$\mathrm{X}=$ Sarkma uzunluğu, $\mathrm{cm}$

$\mathrm{G}=0,1 * \mathrm{~W}^{*} \mathrm{C}^{3}$

$\mathrm{G}=$ Eğilme dayanımı, mg.cm 
$\mathrm{W}=$ Kumaşın metrekare ağırlığ $1, \mathrm{~g} / \mathrm{m}^{2}$

Kumaşın genel eğilme dayanımı $G_{o}, 3$ nolu eşitlikle hesaplanmaktadır.

$\mathrm{G}_{\mathrm{o}}=\left(\mathrm{G}_{\mathrm{a}} * \mathrm{G}_{\mathrm{c}}\right)^{1 / 2}$

Çizelge 8'de test sonuçları yer almaktadır. Şekil 4'te ise eğik düzlem metoduyla yapılan eğilme dayanımı test düzeneği gösterilmiştir.

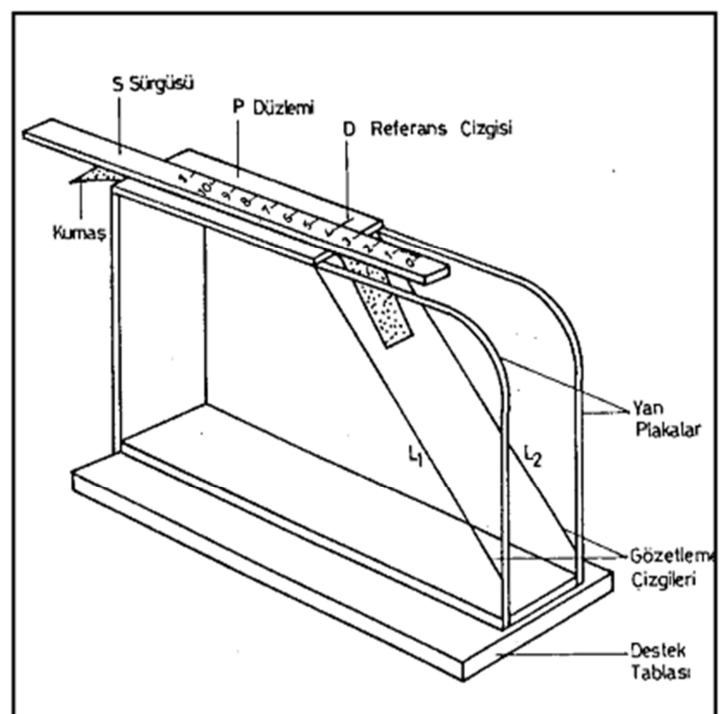

Şekil 4. Eğik düzlem metoduyla yapılan eğilme dayanımı test düzeneği [18]

\section{BULGULAR}

Tüketici kullanımı sonrası geri dönüştürülmüş denim kumaş (PC denim) ve orijinal pamuklu denim kumaş (REF denim) standart atmosfer koşullarında (\%65 Bağıl Nem ve $20{ }^{\circ} \mathrm{C}$ sıcaklık) kondüsyonlandıktan sonra bazı konfor testlerine tabi tutulmuştur.

Yıkama sonrası atkı ve çözgü yönlerindeki çekme yüzdeleri Çizelge 4'te verilmiştir. Kumaşların yıkama sonrası gramaj, sıklık ve kalınlık özellikleri de Çizelge 5'te karşılaştırılmıştır.

Yıkama sonrası kumaş çektiği için birim alana daha fazla iplik düşmektedir ve bu da kumaşların kalınlık, sıklık ve birim alanının gramaj değerlerinde artışa sebep olmuştur.

Çizelge 4. Yıkama sonrası boyut değişsiminin tayini $(\%)$

\begin{tabular}{|c|c|c|c|c|}
\hline \multirow{2}{*}{ Ölçüm No } & \multicolumn{2}{|c|}{ Yıkama sonrası boyut değişimi (\%) } \\
\cline { 2 - 5 } & \multicolumn{2}{|c|}{ REF Denim } & \multicolumn{2}{c|}{ PC Denim } \\
\cline { 2 - 5 } & $\begin{array}{c}\text { Çözgü } \\
\text { yönü }\end{array}$ & $\begin{array}{c}\text { Atk1 } \\
\text { yönü }\end{array}$ & $\begin{array}{c}\text { Çözgü } \\
\text { yönü }\end{array}$ & $\begin{array}{c}\text { Atk1 } \\
\text { yönü }\end{array}$ \\
\hline 1 & 6 & 5 & 6 & 5 \\
\hline 2 & 5 & 7 & 7 & 7 \\
\hline 3 & 4 & 5 & 3 & 8 \\
\hline 4 & 5 & 6 & 5 & 6 \\
\hline 5 & 4 & 4 & 5 & 4 \\
\hline 6 & 5 & 8 & 5 & 5 \\
\hline 7 & 2 & 7 & 5 & 7 \\
\hline 8 & 5 & 5 & 5 & 5 \\
\hline Ortalama & $\mathbf{4 , 5 0}$ & $\mathbf{5 , 8 0}$ & $\mathbf{5 , 1 0}$ & $\mathbf{5 , 8 0}$ \\
\hline $\begin{array}{c}\text { Standart } \\
\text { Sapma }\end{array}$ & $\mathbf{0 , 1 1 9}$ & $\mathbf{0 , 1 3 5}$ & $\mathbf{0 , 1 1 2}$ & $\mathbf{0 , 1 3 5}$ \\
\hline
\end{tabular}

Çizelge 5. Numunelerin fiziksel özellikleri

\begin{tabular}{|l|c|c|c|c|}
\hline & \multicolumn{2}{|c|}{ Yıkama Öncesi } & \multicolumn{2}{c|}{ Ylkama Sonrası } \\
\cline { 2 - 5 } & $\begin{array}{c}\text { REF } \\
\text { Denim }\end{array}$ & $\begin{array}{c}\text { PC } \\
\text { Denim }\end{array}$ & $\begin{array}{c}\text { REF } \\
\text { Denim }\end{array}$ & $\begin{array}{c}\text { PC } \\
\text { Denim }\end{array}$ \\
\hline Gramaj $\left(\mathrm{g} / \mathrm{m}^{2}\right)$ & 399,3 & 411,48 & 445,8 & 436,2 \\
\hline Kalınlık $(\mathrm{cm})$ & 0,73 & 0,728 & 0,918 & 0,904 \\
\hline $\begin{array}{l}\text { Atk1 S1klığ1 } \\
\text { (tel/cm) }\end{array}$ & 20 & 17 & 20 & 22 \\
\hline $\begin{array}{l}\text { Çözgü S1klığ1 } \\
\text { (tel/cm) }\end{array}$ & 26 & 27 & 27 & 29 \\
\hline
\end{tabular}

Çizelge 6'dan görüldüğü gibi, tüketici sonrası geri dönüşüm denim kumaşın (PC denim) hava geçirgenlik değeri standart denim kumaşa (REF denim) göre yaklaşık \%30 oranında daha düşük çıkmıştır. Geri dönüşüm elyafın kullanımında, tüketici sonrası atık olan konfeksiyon ürünlerinin sökülüp küçük parçalara kırpılıp sonra geri dönüşüm pamuk işlem adımlarının takip edilerek yeniden hammadde olarak karışımda kullanılması, PC denim için, homojen olmayan bir yapının öngörülemeyen bir takım olumsuz katkılarının dikkate alınmasını ortaya koymaktadır. Bu sebeple $\% 100$ tüketici sonrası geri dönüşüm elyaftan denim üretimi yerine, \%10-\%30 aralığında karışım olacak şekilde üretimde hammaddeye katk1 tercih edilmektedir.

Sonuçlar Çizelge 7 ve Şekil 5'te gösterilmiştir. 
Çizelge 6. Hava geçirgenliği sonuçları (mm/s)

\begin{tabular}{|c|c|c|}
\hline Ölçüm No & REF Denim & PC Denim \\
\hline 1 & 72,61 & 50,10 \\
\hline 2 & 72,61 & 48,17 \\
\hline 3 & 74,78 & 48,64 \\
\hline 4 & 79,52 & 53,30 \\
\hline 5 & 73,68 & 52,19 \\
\hline 6 & 77,08 & 51,65 \\
\hline 7 & 74,78 & 53,30 \\
\hline 8 & 74,78 & 58,26 \\
\hline 9 & 75,00 & 55,67 \\
\hline 10 & 80,81 & 57,59 \\
\hline Ort. & $\mathbf{7 5 , 5 6}$ & $\mathbf{5 2 , 8 9}$ \\
\hline St.Sap. & $\mathbf{2 , 6 2}$ & $\mathbf{3 , 3 0}$ \\
\hline
\end{tabular}

Tüketici sonrası geri dönüşüm denim kumaşın (PC denim) eğilme dayanımı referans denimden daha düşük tespit edilmiştir. PC denimde, \%20 tüketici sonrası geri dönüşüm elyafı olarak çözgü ipliği üretimine katıldığı düşünüldüğünde, bu tür kumaşlar sadece pamuklu giysilerden değil, elastan, polyester gibi sentetik hammaddelerin bulunduğu karışımlı kumaşlardan da elde edilebileceği için, hammaddenin geri dönüşüm aşamasında gördüğü işlemler sonucunda elyaf kalitesinin \%100 orijinal pamuk elyafindan elde edilen denim kumaştan (REF denim) daha yumuşak bir tutumun ortaya çıkmasını sağladığı kanaati oluşmuştur.

Çizelge 7. Numunelerin eğilme dayanımları

\begin{tabular}{|c|c|c|c|c|}
\hline \multirow{2}{*}{$\begin{array}{c}\text { Ölçüm } \\
\text { No }\end{array}$} & \multicolumn{2}{|c|}{ REF Denim } & \multicolumn{2}{c|}{ PC Denim } \\
\cline { 2 - 5 } & $\begin{array}{c}\text { Ön } \\
\text { Yüz }\end{array}$ & $\begin{array}{c}\text { Arka } \\
\text { Yüz }\end{array}$ & $\begin{array}{c}\text { Ön } \\
\text { Yüz }\end{array}$ & $\begin{array}{c}\text { Arka } \\
\text { Yüz }\end{array}$ \\
\hline 1 & 1,316 & 1,206 & 1,005 & 1,078 \\
\hline 2 & 1,605 & 1,402 & 1,426 & 1,207 \\
\hline 3 & 1,46 & 1,156 & 1,084 & 1,395 \\
\hline 4 & 1,418 & 1,274 & 1,520 & 1,366 \\
\hline 5 & 1,457 & 1,308 & 1,655 & 1,188 \\
\hline Ort. & $\mathbf{1 , 4 5 1}$ & $\mathbf{1 , 2 6 9}$ & $\mathbf{1 , 3 3 8}$ & $\mathbf{1 , 2 4 7}$ \\
\hline St.Sap. & $\mathbf{0 , 0 9 3}$ & $\mathbf{0 , 0 8 5}$ & $\mathbf{0 , 2 5 2}$ & $\mathbf{0 , 1 1 8}$ \\
\hline
\end{tabular}

Numunelerin SEM- Taramalı elektron mikroskobu yardımıyla 28, 60 ve 1000 büyütme oranları kullanarak alınan görüntüleri Çizelge 9'da gösterilmiştir.

\section{Yük Değerleri (kg-f)}

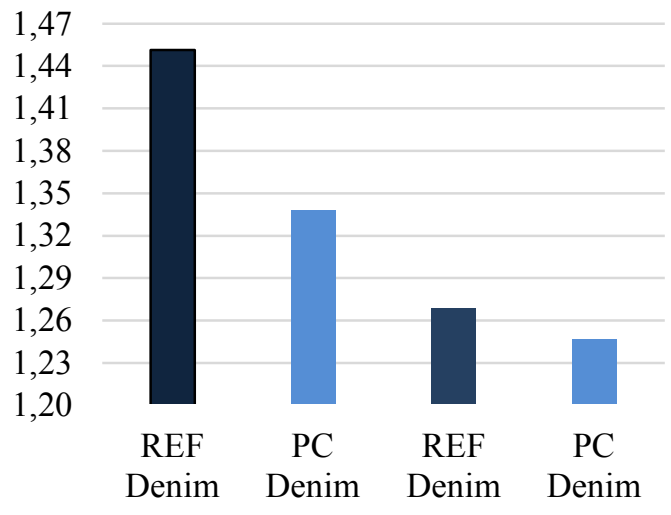

Ön Yüz

Arka Yüz

Şekil 5. Eğilme dayanımı test sonuçları grafiği

Çizelge 8. Numunelerin eğilme dayanımları

\begin{tabular}{|c|c|c|c|c|}
\hline \multirow{2}{*}{$\begin{array}{c}\text { Ölçülen } \\
\text { özellikler }\end{array}$} & \multicolumn{2}{|c|}{ REF Denim } & \multicolumn{2}{|c|}{ PC Denim } \\
\hline & Atkı & Çözgü & Atkı & Çözgü \\
\hline 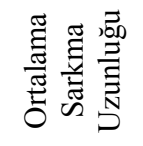 & 5,750 & 7,900 & 5,580 & 6,880 \\
\hline 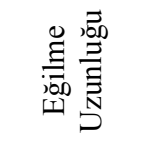 & 2,875 & 3,950 & 2,790 & 3,440 \\
\hline 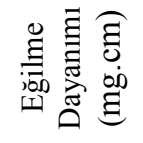 & 948,883 & 2460,881 & 893,637 & 1635,036 \\
\hline 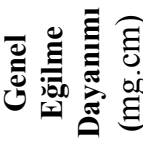 & \multicolumn{2}{|c|}{1528,1} & \multicolumn{2}{|c|}{1223,468} \\
\hline
\end{tabular}


Çizelge 9. Numunelerin SEM görüntüleri

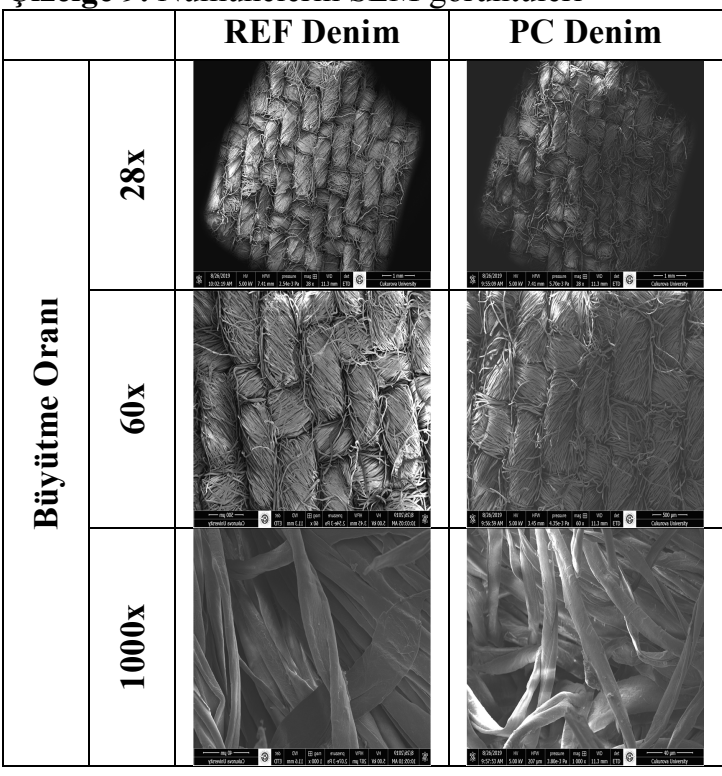

\section{SONUÇLAR}

Hazır giyim sektörü gibi kumaş atıklarının geçmişten beri değerlendirildiği sektörde, tüketici kullanımı sonrası giysilerin de geri dönüşüm işlemine tabi tutulması son yıllarda üzerinde çalışılan bir konudur. Tüketici sonrası geri dönüşümle yeniden hayat bulan bu tür hazır giyim ürünleri tüketiciler için de ilgi çekici olmaya başlamış ve çevre dostu olabilmek adına bu konuya duyarlılık gösterilmeye başlanmıştır.

Deneysel olarak yürütülen bu çalışmada, tüketici kullanımı sonrası geri dönüştürülmüş elyaflar kullanılarak üretilen denim kumaş (PC denim) ile aynı konstrüksiyondaki orijinal denim kumaşın (REF denim) bazı konfor özellikleri tespit edilerek birbirleriyle karşılaştırılmıştır.

Buna göre;

$\checkmark$ PC denim ve REF denim kumaşlar arasında hem atkı yönünde hem çözgü yönünde belirgin bir kumaş çekmesi farkı görülmemiştir. Geri dönüştürülmüş elyaf çözgü ipliği harmanına karıştırılarak kullanıldığı için, PC denim kumaşın çözgü yönü kumaş çekme oranının daha yüksek olduğu görülmektedir. Yıkama sonrasında kumaşlar çektiği için birim alana daha fazla iplik düşmektedir ve bu da kumaşların kalınlık, sıklık ve metre kare ağırlık (gramaj) değerlerinde artışa sebep olmaktadır.

$\checkmark$ Hava geçirgenliği özelliğinde tekstil yüzeylerinin ham maddesi önemli bir paya sahiptir. Çalışmada kullanılan PC denim kumaş sadece pamuklu kumaşlardan değil, kısmen de olsa elastan, polyester gibi sentetik hammaddeler bulunan kumaşlardan da elde edilebileceği için, PC denim kumaşın hava geçirgenlik değeri standart denim kumaşa göre daha düşük çıkmıştır. Ayrıca iplikteki kalın yer $(+50)$ oranı PC denimde daha yüksek olduğu (iplikler daha kalın olduğundan) için birim uzunluğa giren örgü kaynaklı gözeneklilik daha azdır. $\mathrm{Bu}$ da hava geçirgenliğini olumsuz etkilemiştir.

Kumaşların eğilme dayanımları 2 farklı metot ile analiz edilmiştir. ASTM dairesel eğilme test metoduna göre dijital pnömatik yumuşaklık test cihazı ile yapılan ölçümlerde REF ve PC denim kumaşların eğilme dayanımları birbirine çok yakın değerler bulunmuştur. Eğik düzlem metodu ile uygulanan deneyde, her iki kumaş türünde de çözgü numunelerinin eğilme dayanımının daha yüksek olduğu tespit edilmiştir. 3/1 dimi örgü yapısı nedeniyle PC ve REF denim kumaşların arka yüzü atk1 yoğunluklu, ön yüzü çözgü yoğunlukludur. Geri dönüştürülmüş elyaflar çözgüde kullanıldığı için bu elyafların kullanımını kumaşın daha yumuşak tutuma sahip olmasına katkı sağladığı düşünülmektedir.

Tek bir pamuklu t-shirt için 2700 litre su harcandığ 1,1 kilogram pamuk üretmek için 20000 litre su gerektiği gerçeği, bir çok bilinçli tüketiciyi kendine gelmesi için zorlamakta, tüketici, seçtiği bu tür ürünlerle de sürdürülebilir bir dünya için kayda değer bir prestij kazanmaktadır. Amaç, üst düzey geri dönüşüm sağlayarak ürüne değer katmak ise, sıfırdan pamuk üretip kıyafet yapmak yerine atık kumaşlardan elde edilen pamuk ile hem doğal kaynaklar duyarsızca kullanılmamış olur hem de enerji ve su tasarrufu sağlanarak doğaya 
verilen zarar önemli ölçüde azaltılır. Farklı ham maddelerden \%100 PC ürünler mevcut olmakla birlikte, son yıllarda özellikle denim sektöründe \%20 tüketici sonrası geri dönüşüm denim ürünler rağbet görmekte ve AR-GE ye önem veren firmalar, \%100 tüketici sonrası geri dönüşüm pamuklu denim çalışmalarına ivme kazandırmaya çalışmaktadır.

Daha az küresel ısınma, daha az kirlilik, dünya ile daha barışık tüketici için SIFIR ATIK, her bireyin misyonu olmalıdır.

\section{TEŞEKKÜR}

Yazarlar olarak bu çalışmada, kumaşların temini için verdiği destekten dolayı BOSSA DENIM'e (ADANA), testlerin yürütülmesinde verdiği laboratuvar desteği için Çukurova Üniversitesi Tekstil Mühendisliği Bölümüne teşekkür ederiz.

\section{KAYNAKLAR}

1. https://www.wordwild.org/industries/cotton erişim tarihi: 06/04/2020

2. https://wikipedia.org, erişim tarihi: 06/04/2020

3. Yücel, S., Tiber, B., 2018. Hazır Giyim Endüstrisinde Sürdürülebilir Moda, Tekstil ve Mühendis, 25(112), 370-380.

4. Roshan P., 2015. Denim, Manufacture, Finishing and Applications, the Textile Institute, Woodhead Publishing Series in Textiles, UK.

5. https://www.denimalliance.org, erişim tarihi: 06/04/2020.

6. Kurtoğlu Necef, Ö., Seventekin, N., Pamuk, M., 2013, Hazır Giyim Sektöründeki Kumaş Kırpıntılarının Geri Dönüşümü Üzerine Bir Çalışma, Tekstil ve Konfeksiyon, 23(3), 286.

7. Doba Kadem, F., 2016. Sürdürülebilir Bir Yaklaşım: Denim Sektöründe Pamuk Atıklarının Geri Dönüşümü Üzerine Bir Çalışma, 12. Ulusal Kimya Mühendisliği Kongresi (UKMK 2016), 23-26 Ağustos 2016, İzmir.

8. Bairagi, N., 2017. Recyling of Post-consumer Apparel Waste in India: Channels for Textile Reuse, Journal of Textile Science
\&Engineering, 8(1), 1-3. DOI:10.4172/21658064.1000331 .

9. Tölek, Ş., Doba Kadem, F., 2017. An Experimental Evaluation About Drying Behavior of Sustainable Denim, 16. Uluslararası Tekstil Teknolojisi ve Kimyasındaki Son Gelişmeler Sempozyumu, 4-6 Mayıs 2017, 105, Bursa.

10. Wangcheng L., Shuyan L., Liu, T., Liu, T., Zhang, J., Liu, H., 2019. Eco-friendly Postconsumer Cotton Waste Recycling for Regenerated Cellulose Fibers, Carbohydrate Polymers, 206(2019), 141-148.

11. Doba Kadem, F., Özdemir, Ş., 2019 Denimde Geri Dönüşüm Uygulamalar1-Tüketici Sonras1 Geri Dönüşüm (Post-Consumer Re-Cycle), Ulusal Çukurova Tekstil KongresiUÇTEK'2019 26-27 Eylül 2019, 501-508, Adana.

12. Bossa Denim ve Spor Giyim İşletmeleri Kataloğu, 2019.

13. TS 391 EN ISO 9237, 1999. TekstilKumaşlarda Hava Geçirgenliğinin Tayini.

14. TS EN ISO 5077, 2012. Tekstil - Y1kama ve Kurutmada Boyut Değişmesinin Tayini.

15. ASTM D1388, 2018. Eğilme Dayanımı (Dijital Pnömatik Yumuşaklık Test Cihazı ile).

16. TS 1409, 1973 Dokunmuş Tekstil Mamullerinin Eğilme Dayanımı Tayini.

17. Gülşen Bakıcı, G., Doba Kadem, F., 2015. An Experimental Study About Sewability and Bending Strenght Properties of Cotton Fabrics, Çukurova Üniversitesi Mühendislik Mimarlık Fakültesi Dergisi, 30(2), 177-182.

18. Çukurova Üniversitesi Mühendislik Fakültesi Tekstil Mühendisliği Laboratuvar Föyleri 2020. 